\title{
Development of Efficient Xylose Fermentation in Saccharomyces cerevisiae: Xylose Isomerase as a Key Component
}

\author{
Antonius J. A. van Maris ${ }^{1} \cdot$ Aaron A. Winkler ${ }^{2} \cdot$ Marko Kuyper $^{2} \cdot$ \\ Wim T. A. M. de Laat ${ }^{3,4} \cdot$ Johannes P. van Dijken $^{1,2} \cdot$ Jack T. Pronk $^{1}(\square)$ \\ ${ }^{1}$ Department of Biotechnology, Delft University of Technology, Julianalaan 67, \\ 2628 BC Delft, The Netherlands \\ J.T.Pronk@TUDelft.NL \\ ${ }^{2}$ Bird Engineering B.V., Westfrankelandsedijk 1, 3115 HG Schiedam, The Netherlands \\ ${ }^{3}$ DSM Anti-Infectives, A. Fleminglaan 1, 2613 AX Delft, The Netherlands \\ ${ }^{4}$ Royal Nedalco, Van Konijnenburgweg 100, 4612 PL Bergen op Zoom, The Netherlands
}

$1 \quad$ Introduction . . . . . . . . . . . . . . . . . . . . . . 180

1.1 Saccharomyces cerevisiae and Fermentation of Lignocellulosic Hydrolysates 180

1.2 Introduction of Heterologous Genes Encoding Xylose Reductase

and Xylitol Dehydrogenase: Redox Restrictions . . . . . . . . . . . . . 182

1.3 Native D-Xylose-Metabolising Enzymes in S. cerevisiae . . . . . . . . . . . 185

1.4 One-Step Conversion of D-Xylose into D-Xylulose via Xylose Isomerase . . 186

2 Xylose Isomerase: Properties and Occurrence f . . . . . . . . . . . . 186

3 Expression of Xylose Isomerases in S. cerevisiae:

a Long and Winding Road . . . . . . . . . . . . . . . . . 187

4 Characterisation of Yeast Strains

with High-Level Functional Expression of a Fungal Xylose Isomerase . . . 190

$5 \quad$ Metabolic Engineering

for Improved Xylose-Isomerase Based D-Xylose Utilisation . . . . . . . . 192

$6 \quad$ Evolutionary Engineering

for Improved Xylose-Isomerase-Based D-Xylose Utilisation . . . . . . . . . 194

6.1 Evolutionary Engineering of D-Xylose-Consuming S. cerevisiae

for Improved Mixed Substrate Utilisation . . . . . . . . . . . . . . . . . . . 194

6.2 Evolutionary Engineering of S. cerevisiae

only Containing Fungal Xylose Isomerase . . . . . . . . . . . . .

7 Towards Industrial Application:

Fermentation Trials with Xylose-Isomerase-Expressing S. cerevisiae . . . . 198

7.1 From the Laboratory to the Real World: Strains and Media . . . . . . . . . 198

7.2 Batch Fermentation of Wheat Straw Hydrolysate . . . . . . . . . . . . . 199

7.3 Fed-Batch Fermentation of Corn Stover Hydrolysate . . . . . . . . . . . 200

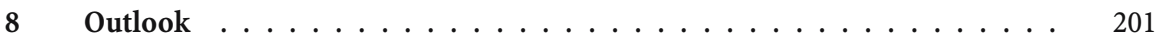

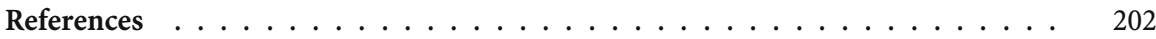


Abstract Metabolic engineering of Saccharomyces cerevisiae for ethanol production from $\mathrm{D}$-xylose, an abundant sugar in plant biomass hydrolysates, has been pursued vigorously for the past 15 years. Whereas wild-type S. cerevisiae cannot ferment D-xylose, the ketoisomer $\mathrm{D}$-xylulose can be metabolised slowly. Conversion of $\mathrm{D}$-xylose into $\mathrm{D}$-xylulose is therefore crucial in metabolic engineering of xylose fermentation by S. cerevisiae. Expression of heterologous xylose reductase and xylitol dehydrogenase does enable $\mathrm{D}$-xylose utilisation, but intrinsic redox constraints of this pathway result in undesirable byproduct formation in the absence of oxygen. In contrast, expression of xylose isomerase (XI, EC 5.3.1.5), which directly interconverts D-xylose and D-xylulose, does not have these constraints. However, several problems with the functional expression of various bacterial and Archaeal XI genes have precluded successful use of XI in yeast metabolic engineering. This changed with the discovery of a fungal XI gene in Piromyces sp. E2, expression of which led to high XI activities in S. cerevisiae. When combined with over-expression of the genes of the non-oxidative pentose phosphate pathway of $S$. cerevisiae, the resulting strain grew anaerobically on D-xylose with a doubling time of ca. $8 \mathrm{~h}$, with the same ethanol yield as on glucose. Additional evolutionary engineering was used to improve the fermentation kinetics of mixed-substrate utilisation, resulting in efficient D-xylose utilisation in synthetic media. Although industrial pilot experiments have already demonstrated high ethanol yields from the D-xylose present in plant biomass hydrolysates, strain robustness, especially with respect to tolerance to inhibitors present in hydrolysates, can still be further improved.

1

Introduction

\section{1}

\section{Saccharomyces cerevisiae and Fermentation of Lignocellulosic Hydrolysates}

The worldwide annual ethanol production via microbial fermentation amounted to ca. $40 \mathrm{Mt}$ in 2005 (according to the Renewable Fuel Association; www.ethanolrfa.org) and is rapidly growing. Although bacteria such as Zymomonas mobilis and engineered Escherichia coli strains are capable of homoethanolic fermentation of sugars [17], the yeast Saccharomyces cerevisiae remains the organism of choice for large-scale industrial production of ethanol. Factors contributing to the popularity of $S$. cerevisiae as an industrial ethanol producer include its high ethanol tolerance, its ability to grow under strictly anaerobic conditions and - an important characteristic distinguishing it from prokaryotic organisms - its insensitivity to bacteriophage contaminations. Moreover, S. cerevisiae grows well at low $\mathrm{pH}$, reducing problems with contamination of industrial processes with, for example, lactic acid bacteria.

Global concern about carbon dioxide emissions and climate change, depletion of oil reserves and geopolitical issues all contribute to a drive to increase the production of ethanol as a renewable transport fuel (see the contribution of Otero et al. in this volume). Presently, ethanol is exclusively produced from the starch or the sucrose fraction of a small number of (edible) agricultural 
crops such as corn, sugar cane, sugar beet and grain. To expand the feedstock range for large-scale ethanol production and to improve productivity, it is of vital importance to enable efficient ethanol production from agricultural residues and other low-value sources of carbohydrates. Feedstocks such as corn stover, bagasse, wheat straw, non-recyclable paper or dedicated crops such as switchgrass represent an enormous potential in terms of available carbohydrates. However, instead of starch and sucrose, the carbohydrates in these feedstocks consist of a complex matrix of cellulose, hemicellulose, pectin and lignin [69].

The use of lignocellulosic raw materials for ethanol production poses a number of major challenges compared to the use of conventional starch- or sucrose-based feedstocks:

(i) Release of monomeric sugars from lignocellulosic biomass requires a mix of physicochemical (extreme $\mathrm{pH}$, high temperature, high pressure) and enzymic polysaccharide (hydrolases) treatments [19,37].

(ii) The resulting lignocellulose hydrolysates contain a wide variety of compounds that may inhibit the fermentation process. These compounds are either formed during the pretreatment process (e.g. furfural and hydroxymethylfurfural) or are biomass constituents that are released during hydrolysis (e.g. acetate, formate) [31, 37, 49, 54].

(iii) Whereas starch- and sucrose-based feedstocks yield hexoses upon hydrolysis, lignocellulosic biomass, and in particular its hemicellulose fraction, also contains large amounts of the pentose sugars D-xylose and $\mathrm{L}$-arabinose. D-Xylose, generally the most abundant pentose, comprises up to $25 \%$ of the total sugar content in some hydrolysates $[24,46,69]$.

Whereas S. cerevisiae spp. can rapidly ferment hexose sugars such as glucose, fructose, mannose and galactose, they cannot grow on nor ferment $\mathrm{D}$-xylose or L-arabinose $[7,69]$. Given the importance of xylose fermentation for the efficient production of ethanol from lignocellulosic biomass $[24,46,69]$, it is not surprising that introduction and optimisation of heterologous pathways for xylose fermentation into S. cerevisiae has long been a hot topic in metabolic engineering of yeast.

Interestingly, it has long been known that $S$. cerevisiae is able to slowly metabolise the pentose sugar $\mathrm{D}$-xylulose $[30,71]$. This keto-isomer of xylose is phosphorylated to D-xylulose-5-phosphate by xylulokinase (XKS1, [57]) and subsequently metabolised via the non-oxidative part of the pentose phosphate pathway and glycolysis. It is therefore logical that strategies for converting D-xylose into D-xylulose are an exhaustively studied topic in the quest for alcoholic fermentation of $\mathrm{D}$-xylose by $S$. cerevisiae. These strategies will be briefly discussed in Sects. 1.2-1.4. 


\section{2}

\section{Introduction of Heterologous Genes Encoding Xylose Reductase and Xylitol Dehydrogenase: Redox Restrictions}

In contrast to $S$. cerevisiae, many yeast species are capable of utilising xylose as the sole carbon and energy source for respiratory growth. However, only few of these yeasts are capable of fermenting xylose to ethanol under oxygen-limited conditions, such as for instance Pichia stipitis and Pachysolen tannophilus [65].

Maybe not surprisingly, xylose-metabolising yeasts have predominantly been isolated from wood-related environments. The pathway for D-xylose metabolism used by these yeasts to convert D-xylose to D-xylulose was first described in 1955 [25] and involves a two-step conversion that involves two oxidoreductases (Fig. 1): xylose reductase (EC 1.1.1.21) and xylitol dehydrogenase (EC 1.1.1.9). The xylose reductase has a strong preference for NADPH, whereas the subsequent oxidation of xylitol via xylitol dehydrogenase produces NADH (Table 1).

Clearly, this difference in cofactor specificity can result in redox imbalance. To generate the NADPH for the xylose reductase reaction, part of the D-xylose carbon must be directed through the oxidative pentose phosphate pathway (involving the glucose-6-phosphate dehydrogenase and 6-phosphogluconate dehydrogenase reactions). While this results in a loss of some carbon as $\mathrm{CO}_{2}$,

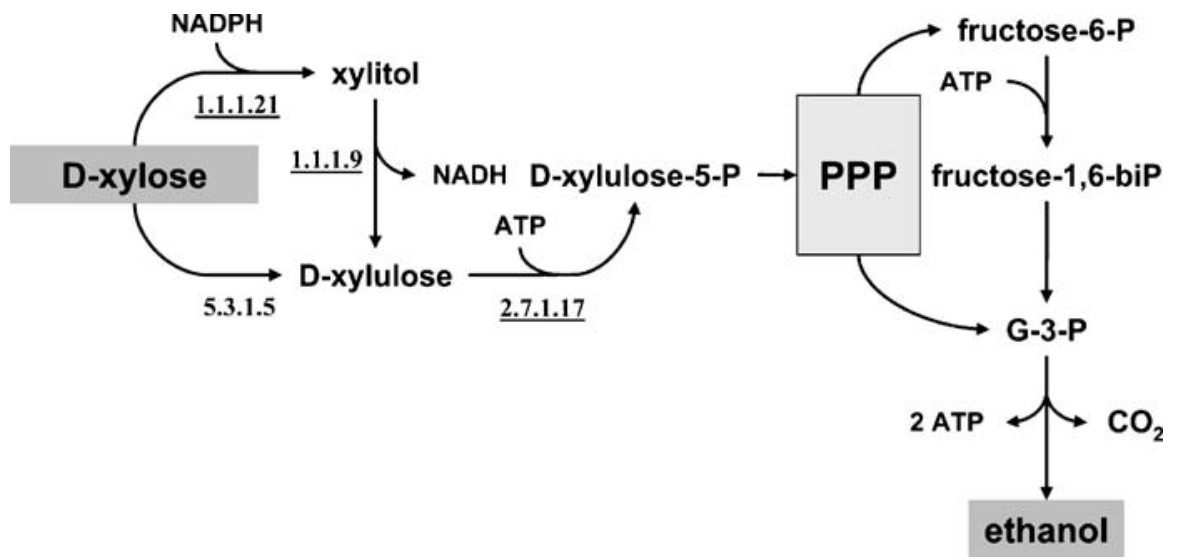

Fig. 1 D-Xylose catabolism in (metabolically engineered) S. cerevisiae strains. Underlined EC numbers represent enzymes/steps present in wild-type $S$. cerevisiae metabolism. The gene names corresponding to the enzymes are given in parentheses: 1.1.1.21, aldose/xylose reductase (GRE3/xyl1); 1.1.1.9, xylitol dehydrogenase (XYL2/xyl2); 2.7.1.17, xylulokinase (XKS1/xyl3); 5.3.1.5, xylose isomerase (xylA). G-3-P glyceraldehyde-3phosphate, $P P P$ pentose phosphate pathway 
Table 1 NADPH-linked and NADH-linked xylose reductase activities in batch cultures of various $\mathrm{D}$-xylose-assimilating yeasts

\begin{tabular}{|c|c|c|c|c|c|}
\hline \multirow[t]{2}{*}{ Organism } & \multirow{2}{*}{$\begin{array}{l}\text { CBS } \\
\text { no. }\end{array}$} & \multicolumn{3}{|c|}{ Specific activity } & \multirow{2}{*}{$\begin{array}{l}\text { Xylose } \\
\text { fermentation }^{a}\end{array}$} \\
\hline & & $\mathrm{NADH}$ & NADPH & Ratio & \\
\hline \multirow[t]{8}{*}{ Candida tenuis } & 615 & 2 & 130 & 0.02 & - \\
\hline & 2226 & 7 & 320 & 0.02 & - \\
\hline & 2885 & $0^{\mathrm{b}}$ & 100 & 0 & - \\
\hline & 4113 & 60 & 120 & 0.5 & + \\
\hline & 4285 & 305 & 670 & 0.5 & + \\
\hline & 4434 & $0^{\mathrm{b}}$ & 485 & 0 & - \\
\hline & 4435 & 340 & 670 & 0.5 & + \\
\hline & 4604 & $0^{\mathrm{b}}$ & 365 & 0 & - \\
\hline Candida shehatae & 5813 & 210 & 480 & 0.4 & + \\
\hline Candida utilis & 621 & $0^{\mathrm{b}}$ & 75 & 0 & - \\
\hline
\end{tabular}

Cells were harvested at mid-exponential growth phase. Enzyme activities are expressed as $\mathrm{nmol}(\mathrm{mg} \text { protein })^{-1} \mathrm{~min}^{-1}$. Data taken from Bruinenberg et al. (1984) [15]

${ }^{\text {a }}$ Results obtained in a fermentation test using a Durham vial

b Not detectable

- No gas production, ethanol less than $0.3 \mathrm{~g} \mathrm{~L}^{-1}$

+ Gas production, ethanol higher than $5.0 \mathrm{gL}^{-1}$

which goes at the expense of the ethanol yield on D-xylose, it enables the efficient regeneration of NADPH [16, 32, 45, 69].

However, the cells have to take additional measures to reoxidise the excess NADH generated in the xylitol dehydrogenase reaction. In the presence of oxygen, this excess NADH can be reoxidised by respiration. This will require accurate dosage of oxygen to prevent full respiration of D-xylose. Such accurate control is difficult to envisage in large-scale processes for ethanol production, which should preferably involve a minimum of aeration to reduce costs.

Under anaerobic conditions, reoxidation of excess NADH can be accomplished via the production of compounds that are more reduced than D-xylose, such as xylitol and/or glycerol. The production of xylitol occurs via xylose reductases, which have a dual co-enzyme specificity and thereby can also use NADH, or alternatively via other aspecific reductases. As this mechanism involves the consumption of one D-xylose for each NADH generated, it has a tremendously negative impact on the ethanol yield from D-xylose [45]. Glycerol production is a well-known redox sink during hexose fermentation and especially under anaerobic conditions, but requires both carbon and ATP [67].

The preference of xylose reductase for NADPH is not only species- but also strain-dependent (Table 1). The in vivo ratio of NADPH over NADH utilisation by xylose reductase and the redox balance requirements determine the 


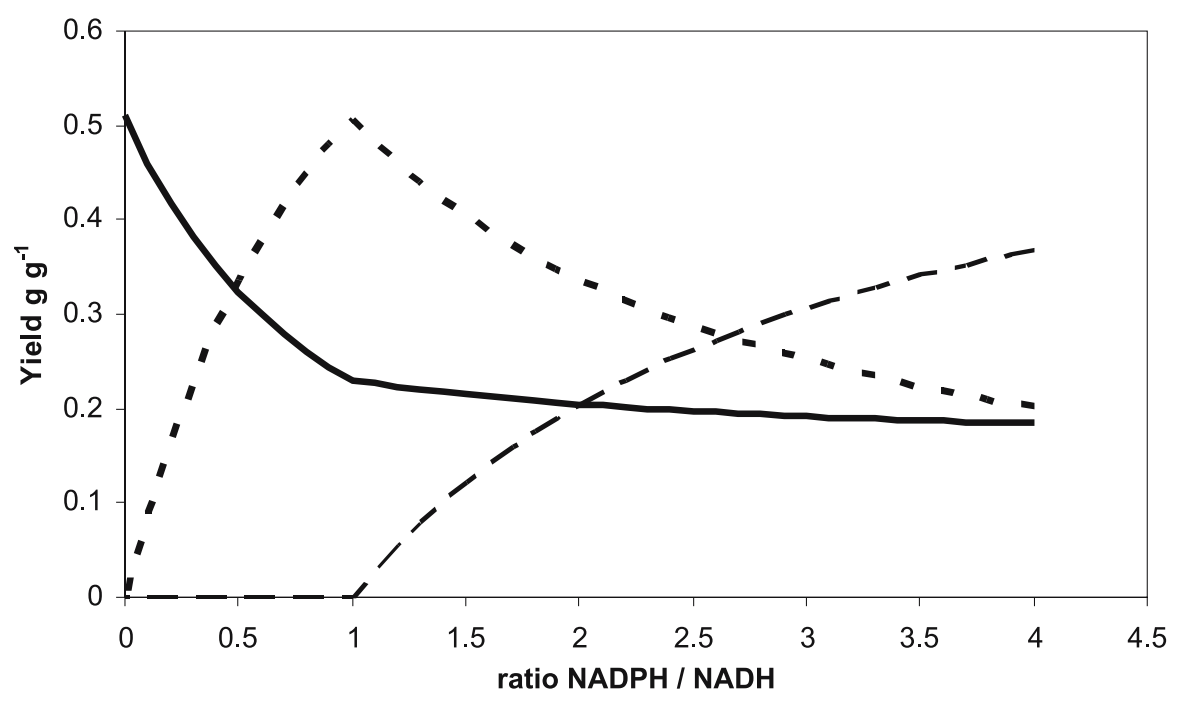

Fig. 2 Calculated ethanol (-), xylitol (- - -) and glycerol (- - -) yields during anaerobic catabolism of $\mathrm{D}$-xylose as a function of the ratio of the fluxes via NADPH-linked and NADH-linked xylose reductase calculated from Eqs. 1, 2 and 3. Assumed is that (ATPusing) glycerol formation does not occur below a ratio of 1 . In other words, NADH is preferentially shuttled into xylitol formation instead of glycerol formation. Above a ratio of 1 there is a stoichiometric necessity for an alternative redox sink such as glycerol formation. At a ratio of 4.0 the ATP yield is zero. Figure from van Maris et al. 2006 [69]

requirement for NADH sinks such as xylitol and glycerol (Fig. 2) in anaerobic cultures $[14,69]$. When this NADPH/NADH ratio equals zero, xylose reductase only uses NADH and thereby consumes all NADH produced in the xylitol dehydrogenase reaction. Since in addition no regeneration of NADPH is required for the xylose reductase reaction, redox-balanced xylose metabolism will occur according to Eq. 1:

$$
\text { Ratio }=0: \quad 6 \text { xylose } \rightarrow 10 \text { ethanol }+10 \mathrm{CO}_{2}+10 \text { ATP } .
$$

At a ratio of one (Eq. 2), one out of every two D-xylose molecules can be further metabolised to ethanol, whereas the other is reduced to xylitol to maintain NADH balance. In addition, some carbon has to be redirected for the generation of NADPH, resulting in the formation of only $9 \mathrm{~mol}$ of ethanol from $12 \mathrm{~mol}$ of D-xylose ( $45 \%$ of the theoretical yield). Following these redox-balance considerations, catabolism via a xylose reductase with a NADPH/NADH-utilisation ratio of one will follow:

$$
\text { Ratio }=1: \quad 12 \text { xylose } \rightarrow 9 \text { ethanol }+12 \mathrm{CO}_{2}+9 \text { ATP }+6 \text { xylitol } .
$$

At ratios above one, NADH-dependent xylitol formation cannot compensate for the production of NADH in the xylitol dehydrogenase reaction and glycerol formation becomes essential for redox balancing [32, 45, 69]. When the xylose 
reductase solely uses NADPH (an infinite NADPH/NADH ratio) this would result in the formation of only $0.5 \mathrm{~mol}$ ethanol per mol of xylose fermented.

$$
\text { Ratio }=\infty: \quad 6 \text { xylose }+3 \mathrm{ATP} \rightarrow 3 \text { ethanol }+6 \text { glycerol }+6 \mathrm{CO}_{2} .
$$

Despite these inherent redox restrictions and ensuing loss of ethanol yield on $\mathrm{D}$-xylose, the expression of xylose reductase and xylitol dehydrogenase has long been the most successful strategy to enable D-xylose consumption by $S$. cerevisiae (elsewhere in this volume, and $[29,32,33,39,63]$ ). Although attempts have been made to change the cofactor specificity of xylose reductase, fermentation properties of a $S$. cerevisiae strain containing this gene are not available [55]. Similarly, expression of a transhydrogenase in S. cerevisiae, with the aim of converting excess NADH into NADPH, did not result in reduced byproduct formation [51]. The latter result is perhaps not altogether surprising as, with $\mathrm{NADPH} / \mathrm{NADP}^{+}$ratios generally being higher than $\mathrm{NADH} / \mathrm{NAD}^{+}$ratios [51], reduction of $\mathrm{NADP}^{+}$with $\mathrm{NADH}$ is thermodynamically unfavourable.

Despite the inherent redox constraints of S. cerevisiae strains based on the xylose reductase/xylitol dehydrogenase strategy, this strategy has resulted in many important insights into the kinetics of $\mathrm{D}$-xylose metabolism by engineered S. cerevisiae strains. These findings include the benefits of overexpression of xylulokinase $[29,56]$, the side role of the $S$. cerevisiae aldose reductase (Gre3) (besides the heterologous dual specificity xylose reductases) in xylitol formation [66], the role of the enzymes of the non-oxidative part of the pentose phosphate pathway [34,43], characterisation of D-xylose transport $[27,62]$ and many studies on the inhibitor tolerance/sensitivity of D-xylose-consuming strains [54]. The latter will be especially crucial for successful application of D-xylose-consuming S. cerevisiae strains for ethanol production from lignocellulosic hydrolysates (see Sect. 7).

\section{3}

\section{Native D-Xylose-Metabolising Enzymes in S. cerevisiae}

Although S. cerevisiae cannot grow on D-xylose as the sole carbon source, its genome does contain genes that code for a non-specific NADH-dependent aldose reductase (GRE3) and for a xylitol dehydrogenase (XYL2). It has been shown that over-expression of these native $S$. cerevisiae genes using endogenous promoters enabled a specific growth rate of $0.01 \mathrm{~h}^{-1}$ on D-xylose in shake flasks [64]. However, in these shake-flask cultures this engineered yeast strain converted $\mathrm{D}$-xylose into xylitol with a yield of $55 \%$. Under anaerobic conditions, precluding respiratory $\mathrm{NAD}^{+}$regeneration, the strain overexpressing the endogenous enzymes was unable to utilise D-xylose [64].

In addition to this metabolic engineering approach, the presence of endogenous genes for D-xylose-converting enzymes has been used in recent experiments by Attfield and Bell (2006), describing a non-recombinant S. cere- 
visiae strain that grows on $\mathrm{D}$-xylose as the sole carbon source in aerobic shake flask cultures. In their study a combination of population genetics and evolutionary engineering $[5,60]$ resulted in an increase in growth rate from extremely low, barely measurable growth rates to a specific growth rate of around $0.12 \mathrm{~h}^{-1}$ (a doubling time of less than $6 \mathrm{~h}$ ) over a period of 1400 days. Apparently, this $S$. cerevisiae strain had evolved in such a way that the very low "background" xylose reductase and xylitol dehydrogenase activities, which were previously described as insufficient for growth on D-xylose [8], increased to levels that did enable growth. Indeed, subsequent analysis of the evolved strain showed that xylose reductase activity had increased fourfold and the xylitol dehydrogenase activity 80 -fold relative to the parental strain. The actual genes that underwent mutation have not yet been characterised. Although this very interesting study underlines the tremendous potential of evolutionary approaches, the selection procedure inevitably resulted in a yeast strain displaying the characteristics of redox imbalance, such as xylitol production.

\section{4 \\ One-Step Conversion of D-Xylose into D-Xylulose via Xylose Isomerase}

In view of the intrinsic redox restrictions associated with the combined introduction of xylose reductase and xylitol dehydrogenase into S. cerevisiae, it is relevant to explore alternative metabolic engineering strategies. As will be discussed below, expression of heterologous genes for xylose isomerase (an enzyme that does not naturally occur in S. cerevisiae) offers such an alternative [14]. In the following sections, we will briefly discuss the properties and taxonomic distribution of xylose isomerases. This will be followed by a brief overview of previous attempts at functional expression of xylose isomerases in S. cerevisiae. We will then discuss how, in the past few years, fast progress has been made due to the discovery of a new, fungal xylose isomerase gene. Finally, we will discuss the status of the xylose isomerase strategy with regard to full-scale industrial application.

\section{2}

\section{Xylose Isomerase: Properties and Occurrence}

Xylose isomerase (XI, D-xylose ketol isomerase, EC 5.3.1.5) catalyses the reversible isomerisation of $\mathrm{D}$-xylose to $\mathrm{D}$-xylulose. This enzyme has been the subject of much applied research because it also catalyses the isomerisation of D-glucose and D-fructose. In this role of "glucose isomerase", xylose isomerase is applied on a huge scale for the production of high-fructose corn syrup and continues to be one of the most abundantly applied industrial enzymes. The high-fructose syrup application has led to intensive screening and protein engineering studies, with increased activity and stability of XIs at el- 
evated temperature as a priority target $[11,23]$. For excellent reviews on the molecular and industrial aspects of XI, the reader is referred to a number of specialised reviews $[4,11,12]$.

In the context of the present paper, several characteristics of XIs are noteworthy. First and foremost, and in contrast to the xylose reductase/xylitol dehydrogenase pathway, the XI reaction does not involve pyridine nucleotide cofactors. As this will entirely circumvent the cofactor regeneration challenges associated with the xylose reductase/xylose dehydrogenase pathway, functional expression of a XI in S. cerevisiae has long been regarded the most promising approach to engineering S. cerevisiae for alcoholic fermentation of D-xylose [14].

XIs generally require divalent cations, but the specificity of the metal requirement is strongly dependent on the source of the enzyme, with many enzymes requiring $\mathrm{Co}^{2+}$, but others $\mathrm{Mn}^{2+}$ or $\mathrm{Mg}^{2+}$ [11]. Although S. cerevisiae has been demonstrated to accumulate cobalt intracellularly [18], it is not clear whether this metal is available in the cytosol or sequestered in, for example, the vacuole. Other aspects with potential relevance for yeast metabolic engineering include the high temperature optimum $\left(60-80^{\circ} \mathrm{C}\right)$ and the relatively high $\mathrm{pH}$ optimum (7.0-9.0) of many of the XIs that have been characterised [11]. As S. cerevisiae is a mesophilic micro-organism with a cytosolic $\mathrm{pH}$ slightly below 7 , intracellular expression of heterologous structural genes for XIs may not always lead to optimal activity.

Even in the pre-genomics era, it was clear that XIs are widespread among prokaryotic micro-organisms, and also occur in several plants [11]. Figure 3 shows a phylogenetic tree of XI gene sequences based on an October 2006 GenBank database search. This phylogenetic tree gives a good indication of the diversity of XI genes and the phylogenetic relationships between sequences from related organisms. With respect to eukaryotes, the tree contains four sequenced XI sequences from the plants Hordeum vulgare, Arabidopsis thaliana, Oryza sativa and Medicago truncatula, which cluster together (Fig. 3). The phylogenetic tree contains only one other eukaryotic XI sequence, namely that of the anaerobic fungus Piromyces sp. E2 [28]. Interestingly, this eukaryotic XI sequence clusters with those of the prokaryotic phylum Bacteroidetes, which has led to the suggestion that the fungus may have acquired XI via horizontal gene transfer [28], as previously suggested for other enzymes in anaerobic fungi [20].

\section{3}

\section{Expression of Xylose Isomerases in S. cerevisiae: a Long and Winding Road}

The expression of a cofactor-independent, heterologous XI is the solution for bypassing the intrinsic redox constraints of the XR/XDH approach. Suc- 
cessful implementation, however, requires an in vivo activity of XI similar to that of key glycolytic enzymes such as hexokinase and phosphofructokinase. In practice, this corresponds to an activity, under physiological conditions, of $0.5-1.0 \mu \mathrm{mol} \mathrm{D}$-xylose converted per milligram soluble cell protein per minute [68]. The apparent simplicity of this objective turned out to be deceptive. In fact, studies on the functional expression of heterologous structural genes for XI in S. cerevisiae now spans roughly two decades.

Expression in S. cerevisiae of the E. coli xylA gene (which clusters with the XI genes from other Proteobacteria, Fig. 3), resulted in no [13] or very low in vitro XI activities [59]. Sarthy et al. (1987) showed that, while the E. coli XylA protein was produced in S. cerevisiae, its specific activity was three orders of magnitude below that of XylA protein produced in E. coli [59]. Improper protein folding, sub-optimal intracellular $\mathrm{pH}$, post-translational modification, inter- or intramolecular disulfide bridge formation and a lack of specific cofactors or metal ions in S. cerevisiae were mentioned as possible causes [59]. However, no single factor was identified that could explain the low activity, and attempts to increase E. coli XI expression levels in S. cerevisiae were unsuccessful [59]. Subsequently, attempts were made to express XI-encoding genes from other prokaryotic phyla. Attempts to express XI genes from Clostridium thermosulfurogenes [48], Bacillus subtilis or Actinoplanes missouriensis [1], which originate from different prokaryotic phyla (Fig. 3), also failed to result in the production of an active XI enzyme in S. cerevisiae.

The first study that achieved significant activities of a heterologous XI enzyme in S. cerevisiae was based on expression of the XI gene from the thermophile Thermus thermophilus [70]. Indeed, an enzyme activity of up to $1.0 \mu \mathrm{mol}(\mathrm{mg} \text { protein })^{-1} \mathrm{~min}^{-1}$ was found in cell extracts of the engineered S. cerevisiae strain. However, this activity was assayed at the optimum temperature for activity of the T. thermophilus XI of $85^{\circ} \mathrm{C}$, which is not compatible with yeast growth or survival. At $30^{\circ} \mathrm{C}$, the optimum temperature for growth of $S$. cerevisiae, activity was only $0.04 \mu \mathrm{mol}(\mathrm{mg} \text { protein })^{-1} \mathrm{~min}^{-1}$ [70]. Although subsequent random mutagenesis resulted in variants of the T. thermophilus XI with improved temperature characteristics [26, 47], in vivo enzyme activities of the T. thermophilus XI in S. cerevisiae strains remained too low to sustain rapid anaerobic growth on D-xylose ( [35], see Sect. 5).

A breakthrough came with the discovery of a XI in an unicellular eukaryote, the anaerobic fungus Piromyces sp. E2 [28]. Expression of this Piromyces xylA gene in S. cerevisiae resulted in high enzyme activities (up to $1.1 \mu \mathrm{mol}(\mathrm{mg} \text { protein })^{-1} \mathrm{~min}^{-1}$ at $30^{\circ} \mathrm{C}[42]$.

The molecular basis for the high functional expression levels obtained with the Piromyces xylA gene remains unclear. We have recently expressed the XI sequence from Bacteroides thetaiotaomicron into S. cerevisiae. This prokaryotic sequence is $83 \%$ identical and $88 \%$ similar to the Piromyces xylA gene. S. cerevisiae strains expressing this prokaryotic XI can utilise D-xylose, albeit 


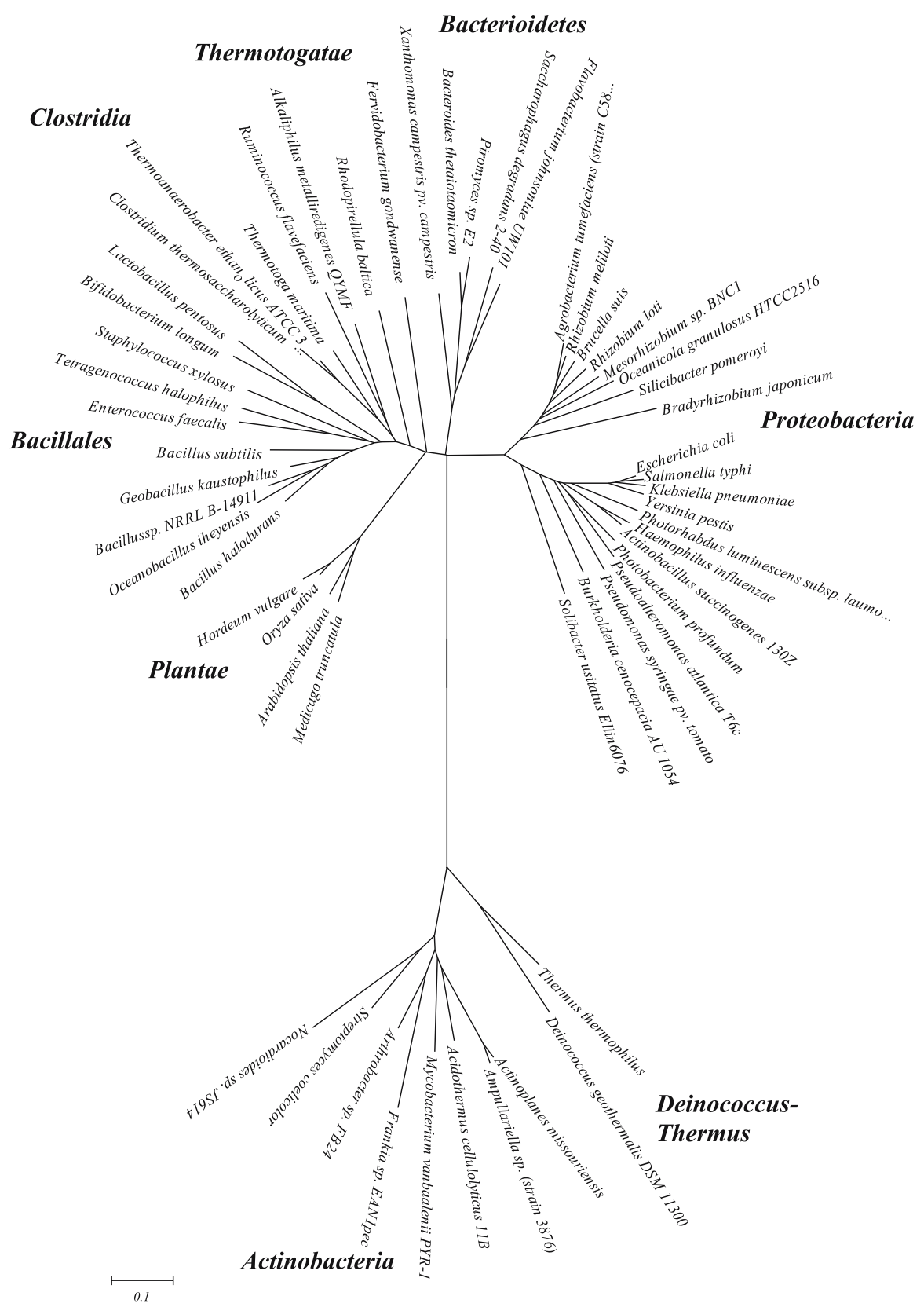

Fig. 3 Phylogram based on the aminoacid sequences of a selection of the xylose isomerases present in BRENDA and GenBank [10,61]. The tree is the consensus of 500 bootstrap repetitions and unrooted. The bar indicates ten substitutions per 100 amino acid residues. Phylogenetic and molecular evolutionary analyses were conducted using MEGA version 3.1 [41] 
at a somewhat lower rate than similar strains expressing the Piromyces xylA gene (A.A. Winkler et al. unpublished). This indicates that its probable evolutionary history (horizontal gene transfer followed by evolutionary adaptation to a eukaryotic host) may not be the sole factor in the successful expression of the Piromyces enzyme.

In terms of GC content and codon usage, the Piromyces xylA gene appears to have favourable characteristics for expression in S. cerevisiae. At $45 \%$, its GC content is much closer to that of S. cerevisiae (39\%), than that of, for example, the T. thermophilus gene (little over $64 \% \mathrm{GC}$ ). Also the high codon bias index of the Piromyces gene for expression in S. cerevisiae ( 0.642 versus -0.018 for the T. thermophilus gene) may contribute to its efficient expression. Future structure-function studies will likely identify critical factors for highlevel functional expression in yeast, in the S. cerevisiae genome as well as in the sequence of heterologous XI genes. However, while of great scientific interest, innovation in D-xylose fermentation is no longer dependent on such research, as the availability of the Piromyces xylA gene has paved the way for metabolic engineering of S. cerevisiae for anaerobic fermentation of $\mathrm{D}$-xylose to ethanol. Recent progress in this area will be discussed in the following paragraphs.

4

\section{Characterisation of Yeast Strains with High-Level Functional Expression of a Fungal Xylose Isomerase}

Expression of the Piromyces sp. E2 XylA gene under control of a strong, constitutive TPI1 promoter on a $2 \mu$-based plasmid (pAKX002) in the haploid laboratory strain $S$. cerevisiae CEN.PK resulted in XI activities ranging from 0.33 to $1.1 \mu \mathrm{mol}$ (mg protein) $)^{-1} \mathrm{~min}^{-1}$ in cell extracts [42]. These activities are similar to those of key enzymes of alcoholic fermentation in glucosefermenting cultures [68]. Apparently, conditions in the cytosol of S. cerevisiae do not preclude accurate folding of the fungal XI, as has previously been reported for the Streptomyces rubiginosus XI [21]. In addition, in contrast to the previously expressed XI from T. thermophilus, the Piromyces XI yielded the above-mentioned activities at a temperature of $30^{\circ} \mathrm{C}$.

Although the high XI activities found in XylA-expressing S. cerevisiae strains provided an excellent starting point for further strain development, they did not as such enable a high specific rate of $\mathrm{D}$-xylose fermentation. In fact, the specific growth rate in aerobic cultures on $20 \mathrm{~g} \mathrm{~L}^{-1} \mathrm{D}$-xylose as the sole carbon source was only $0.005 \mathrm{~h}^{-1}$ (Fig. 4). A similar very low specific growth rate was found in earlier engineered $S$. cerevisiae strains that expressed the $P$. stipitis xylose reductase and xylitol dehydrogenase genes [38, 39]. The low rate of $D$-xylose conversion in strains with a high XI activity suggested that $\mathrm{D}$-xylose consumption was either controlled by $\mathrm{D}$-xylose transport or by reactions downstream from D-xylulose. 


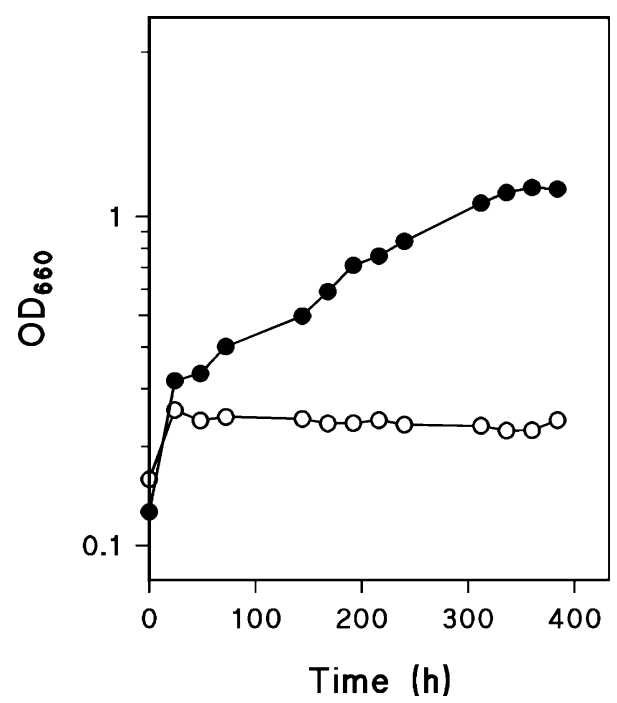

Fig. 4 Growth of S. cerevisiae RWB 202 (•) (CEN.PK 113-5D with pAKX002), expressing Piromyces xylose isomerase, and the reference strain CEN.PK113-7D (O) in shake-flask cultures on synthetic medium with $20 \mathrm{~g} \mathrm{~L}^{-1}$ D-xylose as the sole carbon source. Data from Kuyper et al. 2003 [42]

Since the low specific growth rates of the Piromyces XylA-expressing strains on D-xylose complicated studies in batch cultures, initial studies on D-xylose consumption kinetics and product formation were performed in anaerobic chemostat cultures grown on glucose-xylose mixtures. Anaerobic chemostat cultivations on glucose alone demonstrated that expression of a heterologous XI did not interfere with product formation during growth on glucose [42]. However, when D-xylose was also included in the medium of the anaerobic glucose-limited chemostat cultures, a significant effect of XylA expression was observed. With $20 \%$ of the added D-xylose being consumed, a significant increase of the ethanol yield on consumed glucose was observed (from $0.40 \mathrm{~g} \mathrm{~g}^{-1}$ to $0.44 \mathrm{~g} \mathrm{~g}^{-1}$ ). Although no labeling studies were performed, it stands to reason that this ethanol was produced from the consumed D-xylose.

Interestingly, these anaerobic chemostat cultures of the XylA-expressing strains excreted significant amounts of D-xylulose. At a specific D-xylose consumption rate of $0.73 \mathrm{mmol}$ (g biomass) $)^{-1} \mathrm{~h}^{-1}$ this yeast excreted $\mathrm{D}$-xylulose at a rate of $0.20 \mathrm{mmol}$ (g biomass) ${ }^{-1} \mathrm{~h}^{-1}$ (corresponding to $30 \%$ of consumed D-xylose), which suggested that reactions downstream of D-xylulose were rate-controlling. Moreover, small amounts of xylitol were produced in these cultivations, suggesting involvement of a non-specific aldose reductase such as encoded by GRE3 [66]. This information on D-xylulose and xylitol production was used in subsequent metabolic engineering attempts to improve the D-xylose consumption rate and to minimise xylitol formation. 


\section{5}

\section{Metabolic Engineering for Improved Xylose-Isomerase Based D-Xylose Utilisation}

Metabolic engineering is defined as the improvement of cellular activities by manipulation of enzymic, transport and regulatory functions of the cell with the use of recombinant DNA technology [6]. After the successful expression of a XI in S. cerevisiae [42], reactions downstream of D-xylulose and the, presumably Gre3-dependent, formation of xylitol were identified as priority targets (see previous section).

As it is unlikely that the high capacity of glycolysis in S. cerevisiae would limit D-xylose fermentation rates; limitations in D-xylose fermentation are likely to reside either in the reaction catalysed by xylulokinase or in one of the four reactions of the non-oxidative pentose phosphate pathway. Modulating the flux through a certain pathway by up-modulation of single enzymes often has little effect, as can be shown by metabolic control analysis [50]. Hence, it was decided to simultaneously increase the levels of all five enzymes. To this end, the S. cerevisiae structural genes encoding xylulokinase (XKS1), ribulose-5-phosphate epimerase (RPE1), transketolase (TKL1), transaldolase (TAL1) and ribulose-5-phosphate isomerase (RPI1) were over-expressed together with the Piromyces sp. E2 XylA gene [43]. Since the non-specific aldose reductase encoded by GRE3 had previously been implicated in xylitol formation by $S$. cerevisiae, this gene was also deleted in the engineered strain $[45,66]$.

Research on pentose metabolism in S. cerevisiae is increasingly impeded by the fact that key biochemical intermediates can no longer be purchased commercially $[35,43]$. While this precluded enzyme-activity assays for several of the over-expressed genes, mRNA analysis indicated that over-expression, either from strong constitutive promoters inserted in front of chromosomal genes or from plasmid-borne expression cassettes, was successful.

Remarkably, the S. cerevisiae strain (RWB 217) harbouring the six overexpressions and single deletion was directly capable of anaerobic growth on $\mathrm{D}$-xylose as the sole carbon source at a growth rate of $0.09 \mathrm{~h}^{-1}$ [43]. Starting with a low-density inoculum, this strain consumed $20 \mathrm{~g} \mathrm{~L}^{-1}$ of D-xylose within $40 \mathrm{~h}$, with an ethanol yield on D-xylose of $0.43 \mathrm{~g} \mathrm{~g}^{-1}$. This ethanol yield, which is lower than the theoretical yield of $0.51 \mathrm{~g} \mathrm{~g}^{-1}$ due to the formation of biomass and glycerol, was virtually identical to the ethanol yield found on glucose in exponentially growing, anaerobic $S$. cerevisiae cultures. Deletion of GRE3 reduced xylitol production to trace amounts $(0.4 \mathrm{mM}$ from $20 \mathrm{~g} \mathrm{~L}^{-1} \mathrm{D}$-xylose), indicating that alternative $\mathrm{D}$-xylose- or D-xylulose reducing enzymes were active at very low rates in this S. cerevisiae background. In the engineered strain, D-xylulose no longer accumulated in the broth, indicating that limitations downstream of $\mathrm{D}$-xylulose had been successfully eliminated. 
In an independent study, Karhumaa et al. (2005) expressed the XI gene from $T$. thermophilus together with the same combination of pentose phosphate pathway enzymes [35]. In these strains the specific activity of XI was $0.008-0.017 \mu \mathrm{mol}(\mathrm{mg} \text { protein })^{-1} \mathrm{~min}^{-1}$ at $30^{\circ} \mathrm{C}$. In contrast to the efficient anaerobic growth of the above-described S. cerevisiae expressing the Piromyces sp. E2 XI, D-xylose consumption by the T. thermophylus XI-containing strain (TMB 3045) was not observed under aerobic conditions. After additional se-
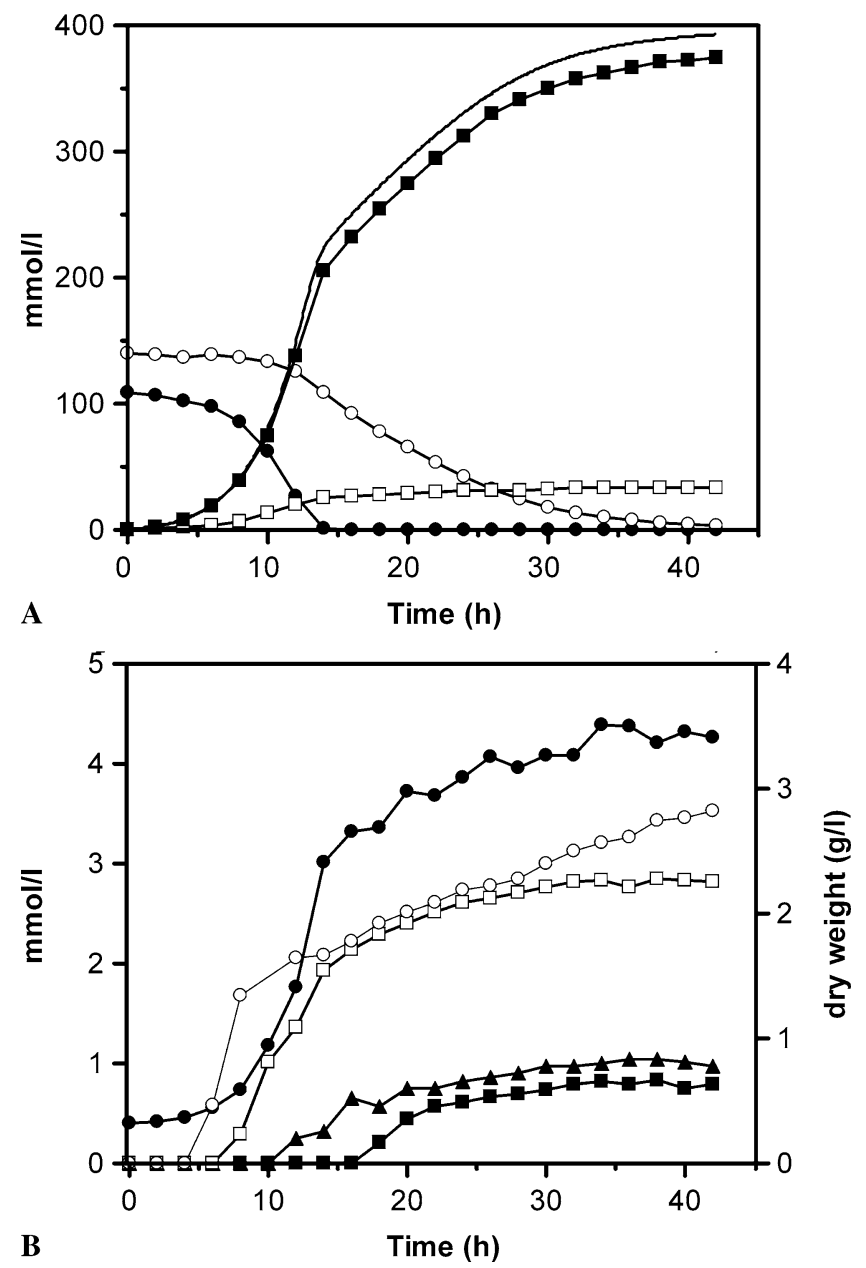

Fig. 5 Anaerobic growth of strain RWB 217 in fermenters on synthetic medium with $20 \mathrm{gL}^{-1}$ glucose and $20 \mathrm{~g} \mathrm{~L}^{-1} \mathrm{D}$-xylose as the carbon source; duplicate experiments differed by less than $5 \%$. a Glucose $(\bullet)$, D-xylose $(O)$, ethanol $(\boldsymbol{\square})$, glycerol $(\square)$ and cumulative $\mathrm{CO}_{2}$ produced per litre as deduced from gas analysis $(-)$. b dry weight $(\bullet)$, acetate (O), xylitol $(\boldsymbol{\square})$, lactate $(\square)$ and succinate $(\boldsymbol{\Lambda})$. Data from Kuyper et al. 2005 [43] 
lection, a strain capable of aerobic growth on $\mathrm{D}$-xylose at a maximum specific growth rate of $0.045 \mathrm{~h}^{-1}$ was isolated (TBM 3050). Confusingly, although the abstract claims anaerobic production of ethanol, the experimental description and results section describe the production of $0.29 \mathrm{~g}$ ethanol ( $\mathrm{g} \mathrm{D}$-xylose $)^{-1}$ at a rate of $2.4 \mathrm{mg}$ (g biomass) $)^{-1} \mathrm{~h}^{-1}$ under oxygen-limited conditions [35]. The ethanol production rates, are more than 400 -fold lower than observed in the Piromyces XylA-based strain [35, 42]. This observation, combined with the interesting observation that TMB 3045 and TMB 3050 display almost identical specific growth rates on $\mathrm{D}$-xylulose, indicates the importance of high-level functional expression of XI for efficient D-xylose fermentation.

In lignocellulosic hydrolysates, D-xylose is generally the second most abundant sugar, with glucose accounting for the majority of the fermentable sugar $[24,46,69]$. Rapid consumption of glucose-xylose mixtures - either sequential or simultaneous - is therefore crucial for successful industrial implementation. When the metabolically engineered strain RWB 217 (described above) was grown in anaerobic batch cultures on mixtures of $20 \mathrm{~g} \mathrm{~L}^{-1}$ glucose and $20 \mathrm{~g} \mathrm{~L}^{-1}$ D-xylose (Fig. 5), sequential utilisation was observed. Although both sugars were consumed within $40 \mathrm{~h}$, D-xylose consumption only commenced when the glucose concentration dropped below $4 \mathrm{gL}^{-1}$. Instead of increasing exponentially, as anticipated based on the kinetics of D-xylose consumption in $\mathrm{D}$-xylose-only cultures, the specific rate of $\mathrm{D}$-xylose consumption decreased over time. Clearly, the kinetics of $\mathrm{D}$-xylose consumption by cells grown in the presence of glucose were sub-optimal. This challenge was addressed by evolutionary engineering.

\section{6}

\section{Evolutionary Engineering for Improved Xylose-Isomerase-Based D-Xylose Utilisation}

\section{1 \\ Evolutionary Engineering of D-Xylose-Consuming S. cerevisiae for Improved Mixed Substrate Utilisation}

The sub-optimal kinetics of mixed-substrate utilisation by the genetically engineered XylA-expressing strain RWB 217 [43] suggested a low affinity $\left(q_{\max } / K_{\mathrm{s}}\right)$ for D-xylose. Soon after the invention of the chemostat it was already established that prolonged cultivation in nutrient-limited chemostats leads to selection of spontaneous mutants with an improved affinity for the growth-limiting nutrient $[52,53]$. This principle, which has since been demonstrated for many micro-organisms and nutrients $[40,58,72,73]$ was applied to improve the affinity of S. cerevisiae RWB 217 for D-xylose [44].

Indeed, during prolonged anaerobic $\mathrm{D}$-xylose-limited chemostat cultivation at a dilution rate of $0.06 \mathrm{~h}^{-1}$, the residual $\mathrm{D}$-xylose concentration decreased 
threefold, indicating that cells with improved affinity for D-xylose were selected for [44]. After $1000 \mathrm{~h}$ (85 generations) of this directed evolution in chemostat cultures, single-colony isolates were tested for batch growth on a mixture of glucose and D-xylose. Although the fermentation kinetics of some of these single-cell lines, as evaluated by carbon dioxide production profiles, were already drastically improved relative to the parental strain (Fig. 6), the $D$-xylose phase remained slower than anticipated based on batch cultivation on D-xylose alone. A further 85 generations of chemostat cultivation resulted in only marginal improvement of the D-xylose consumption characteristics.

To select for further improvement of D-xylose fermentation kinetics, an additional evolutionary engineering strategy was applied, which involved sequential anaerobic batch cultivation on glucose-xylose mixtures [44]. To maximise the number of generations that the cells grow on D-xylose, the D-xylose concentration in the cultures was raised to $90 \mathrm{~g} \mathrm{~L}^{-1}$, with a glucose concentration of $20 \mathrm{~g} \mathrm{~L}^{-1}$. After 20 cycles, the evolved culture was capable of complete anaerobic conversion of a mixture of $20 \mathrm{~g} \mathrm{~L}^{-1}$ glucose and $20 \mathrm{~g} \mathrm{~L}^{-1}$ D-xylose in about $20 \mathrm{~h}$, with an inoculum size of $5 \%(\mathrm{v} / \mathrm{v})$ [44].

Characterisation of the resulting strain RWB 218 (derived from single colony isolate) showed that D-xylose consumption followed the consumption of glucose rapidly (Fig. 7). The $D$-xylose consumption rate observed in these cultures was $0.9 \mathrm{~g}$ D-xylose $(\mathrm{g} \text { dry weight })^{-1} \mathrm{~h}^{-1}$. This evolved XI-based strain, in contrast to strains based on xylose reductase and xylitol dehydrogenase, produced only $0.45 \mathrm{mM}$ of xylitol, indicating that redox imbalance does

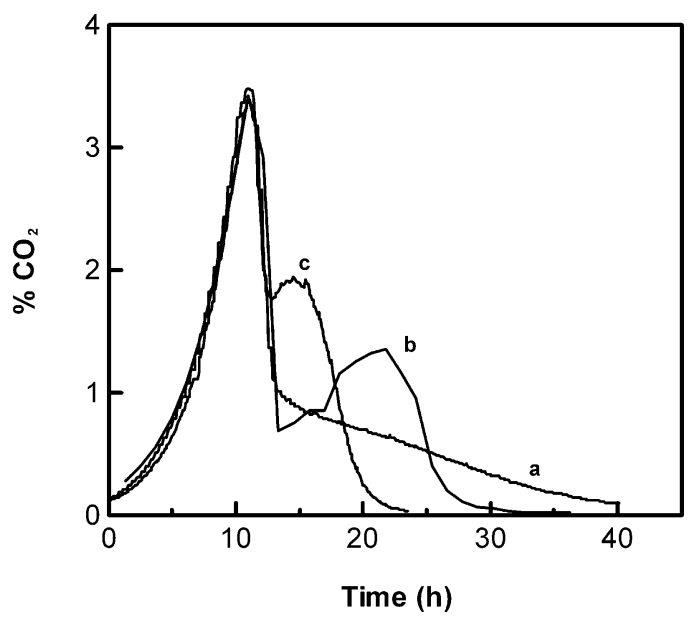

Fig. $6 \mathrm{CO}_{2}$ production profiles, per litre culture, as measured in off gas of anaerobic fermenter batch cultures with $20 \mathrm{~g} \mathrm{~L}^{-1}$ glucose and D-xylose each. Profiles have been aligned on the glucose consumption peak to eliminate variations in initial biomass. $a$ RWB 217, $b$ culture after chemostat selection, $c$ RWB 218. Initial biomass concentrations were $0.20 \pm$ $0.05 \mathrm{~g} \mathrm{~L}^{-1}$. Data from Kuyper et al. 2005 [44] 


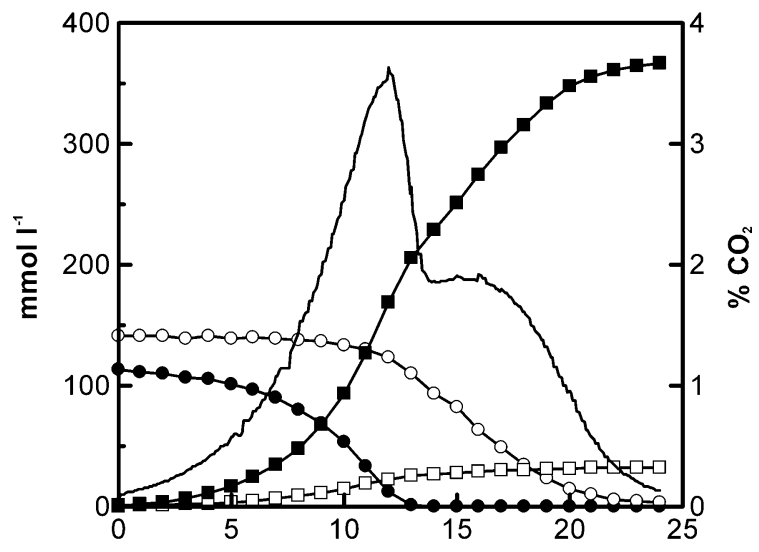

A

Time (h)

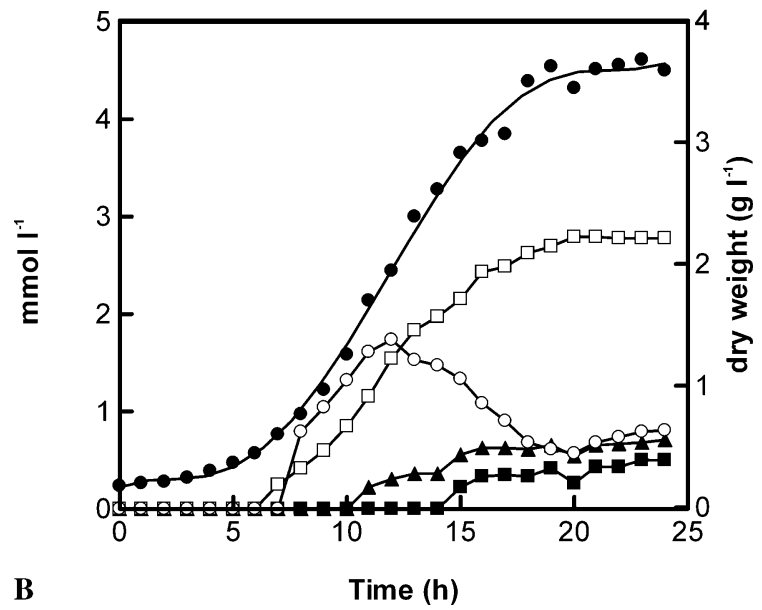

Fig. 7 Typical graph of anaerobic growth of strain RWB 218 in fermenters on synthetic medium with $20 \mathrm{~g} \mathrm{~L}^{-1}$ glucose and $\mathrm{D}$-xylose each as the carbon source, duplicate experiments differed by less than $5 \%$. a Glucose $(\bullet)$, D-xylose $(O)$, ethanol $(\boldsymbol{\square})$, glycerol $(\square)$ and $\% \mathrm{CO}_{2}$ measured in off gas per litre culture $(-)$. b Dry weight $(\bullet)$, acetate $(0)$, xylitol $(\square)$, D-lactate $(\square)$ and succinate $(\boldsymbol{\Lambda})$. Initial biomass concentration was $0.17 \mathrm{~g} \mathrm{~L}^{-1}$. Data from Kuyper et al. 2005 [44]

not occur during alcoholic fermentation of $\mathrm{D}$-xylose. The ethanol yield on total sugar in batch cultures co-fermenting glucose and D-xylose was typically $0.40 \mathrm{~g} \mathrm{~g}^{-1}$, which is identical to the ethanol yield that would be achieved in glucose-grown cultures in a similar set-up. Even when tested in more concentrated sugar mixtures ( $100 \mathrm{~g} \mathrm{~L}^{-1}$ glucose and $25 \mathrm{~g} \mathrm{~L}^{-1} \mathrm{D}$-xylose), resembling an industrial situation, this strain consumed both sugars within $24 \mathrm{~h}$, starting with $1.1 \mathrm{~g} \mathrm{~L}^{-1}$ yeast dry weight as the inoculum [44]. 
With evolutionary engineering as a proven tool for obtaining (yeast) strains with improved properties, a full understanding of the underlying molecular changes becomes the next challenge. In an attempt to unravel the changes between the original metabolically engineered and the subsequently evolved Piromyces XI-based strains, anaerobic chemostat cultivations on D-xylose as the sole carbon source were used as the basis for transcriptome analysis with Affymetrix DNA arrays (J.T. Pronk, unpublished data). The most striking observation amongst the genes with a changed transcript level was the representation of various members of the hexose transport family, including HXT1, HXT2 and HXT4. Interestingly, HXT1 and HXT4 have been associated with D-xylose transport in previous studies $[27,62]$. To investigate whether the improved fermentation characteristics were indeed due to changes in sugar transport, zero trans-influx assays were performed using both the strain that was only metabolically engineered and the subsequently evolved strain [44]. The D-xylose uptake kinetics obtained for the metabolically engineered strain $\left(K_{\mathrm{m}} 132 \mathrm{mM}, V_{\max } 15.8 \mathrm{mmol}(\mathrm{g} \text { dry weight })^{-1} \mathrm{~h}^{-1}\right)$ were in agreement with other studies [22,39]. Strikingly, the D-xylose uptake kinetics of the evolved strain had changed drastically, with a $25 \%$ reduction in the $K_{\mathrm{m}}$ (to $99 \mathrm{mM}$ ) and a twofold increase of $V_{\max }$ to $32 \mathrm{mmol}$ (g dry weight $)^{-1} \mathrm{~h}^{-1}$.

\section{2}

\section{Evolutionary Engineering of S. cerevisiae only Containing Fungal Xylose Isomerase}

After the proof of principle of XI expression in S. cerevisiae, not only metabolic engineering, but also evolutionary engineering was applied to improve the rate of D-xylose utilisation of a strain solely over-expressing XI [44]. Since improvement of the aerobic consumption rate was initially the target of this selection experiment, serial transfer in a shake flask was chosen as the cultivation condition of this evolution run. Indeed, after 30 serial transfers, the specific growth rate of this culture improved drastically (24-fold) from $0.005 \mathrm{~h}^{-1}$ to $0.12 \mathrm{~h}^{-1}$ (Fig. 8). However, a strain isolated from this selection experiment was not yet capable of anaerobic growth. Therefore, an additional ten selection rounds were performed in oxygen-limited batch cultures, finally followed by ten cycles in an anaerobic sequencing batch reactor. From this culture a single colony was isolated (named RWB 202-AFX, for anaerobic fermentation of D-xylose based on strain RWB 202) and used for further characterisation of the end product of this evolutionary engineering.

It was shown that only the expression of a XI, followed by evolutionary engineering for anaerobic growth, can also result in a $S$. cerevisiae strain that can grow on $2 \% \mathrm{D}$-xylose as the sole carbon source, with a growth rate of $0.03 \mathrm{~h}^{-1}$ in anaerobic batch fermentations [45]. However, although this strain displayed a good ethanol yield on D-xylose $\left(0.42 \mathrm{~g} \mathrm{~g}^{-1}\right)$ and very low production of xylitol $(2.8 \mathrm{mM})$, the obtained growth rate, and therefore ethanol 


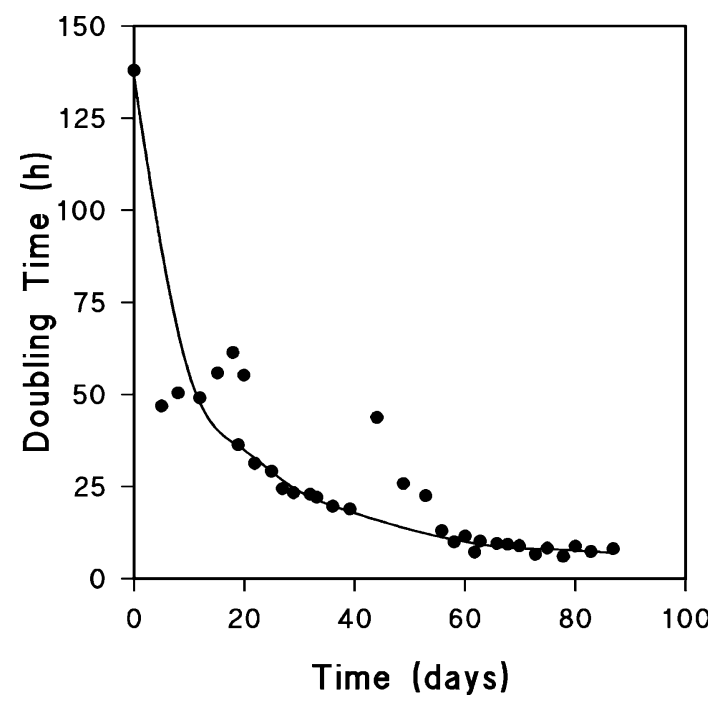

Fig. 8 Doubling time during serial transfer of S. cerevisiae RWB 202 in shake-flask cultures on synthetic medium with xylose. Each data point represents the doubling time of a single serial-transfer flask estimated from the $\mathrm{OD}_{660}$ measured at inoculation and at the time of the next transfer. Occasional transfer of cultures after they had reached stationary phase probably accounts for the unexpectedly high estimated doubling times in some of the cultures. Data from Kuyper et al. 2004 [45]

production rate, were insufficient to allow economically viable industrial application. During these batch cultivations, small amounts of D-xylulose (up to $8 \mathrm{mM}$ ) were still excreted into the broth, indicating that evolutionary engineering alone did not fully overcome the metabolic limitations downstream of this metabolite. This result indicates that although evolutionary engineering is a very powerful tool, it has limitations and, in this case, the combination of knowledge-based metabolic engineering (Sect. 5) combined with evolutionary engineering (Sect. 6.1) resulted in more desirable attributes and higher ethanol production rates.

\section{7}

\section{Towards Industrial Application:}

Fermentation Trials with Xylose-Isomerase-Expressing S. cerevisiae

\section{1}

\section{From the Laboratory to the Real World: Strains and Media}

Successful expression of XI in S. cerevisiae enabled further engineering for high-yield production of ethanol from D-xylose under anaerobic conditions. D-Xylose fermentation rates reported for S. cerevisiae strains based on the 
Piromyces sp. E2 XI were, in principle, sufficiently high for industrial implementation. However, the studies on these strains that have hitherto been cited in this review were all performed under "academic" conditions. These involved the use of defined synthetic media controlled at $\mathrm{pH} 5.0$ and, perhaps most importantly, the absence of inhibitors that are characteristic for real-life plant biomass hydrolysates [31, 37, 49, 54].

The S. cerevisiae strains expressing the Piromyces sp. E2 XI are based on the $S$. cerevisiae CEN.PK platform. Interestingly, preliminary tests showed that the parental strain CEN.PK113-7D demonstrated an almost similar performance in industrial-grade molasses compared with industrial bakers' yeast strains. Moreover, deletion of the GRE3 gene (which encodes a non-specific aldose reductase, [66]) was not detrimental for performance in molasses-based industrial fermentations (W. de Laat, unpublished data). Therefore, trials to test the glucose/xylose fermenting strain $S$. cerevisiae RWB 218 [44] were initiated in both wheat straw and corn stover hydrolysates. Results from these fermentation trials will be briefly discussed below.

\section{2}

\section{Batch Fermentation of Wheat Straw Hydrolysate}

Wheat straw is an abundant lignocellulosic crop residue with potential as a feedstock for ethanol production, especially in Canada and Europe. Wheat straw hydrolysate was therefore selected as one of the fermentation feedstocks for evaluating the fermentation characteristics of S. cerevisiae RWB 218 under industrially relevant conditions (W. de Laat, unpublished data). Wheat straw was pretreated using steam explosion (Sunopta, Canada). The pulp thus obtained was then hydrolysed enzymically at $\mathrm{pH} 5.0$ with cellulases and hemicellulases, yielding a hydrolysate that contained $50 \mathrm{~g} \mathrm{~L}^{-1}$ glucose, $20 \mathrm{~g} \mathrm{~L}^{-1}$ $\mathrm{D}$-xylose, $6 \mathrm{~g} \mathrm{~L}^{-1}$ arabinose and $6 \mathrm{~g} \mathrm{~L}^{-1}$ of disaccharides (cellobiose, melibiose, maltose and sucrose, indicated as DP-2 in Table 2). The hydrolysate, which

Table 2 Characteristics of a batch fermentation of the D-xylose fermenting strain RWB 218 on wheat straw hydrolysate with $0.4 \mathrm{gL}^{-1}$ ammoniumphosphate as the only nutrient addition

\begin{tabular}{lllllll}
\hline $\begin{array}{l}\text { Time } \\
(\mathrm{h})\end{array}$ & $\begin{array}{l}\text { Total sugar } \\
\left(\mathrm{g} \mathrm{L}^{-1}\right)\end{array}$ & $\begin{array}{l}\mathrm{DP} 2 \\
\left(\mathrm{~g} \mathrm{~L}^{-1}\right)\end{array}$ & $\begin{array}{l}\text { Glucose } \\
\left(\mathrm{g} \mathrm{L}^{-1}\right)\end{array}$ & $\begin{array}{l}\text { Xylose } \\
\left(\mathrm{g} \mathrm{L}^{-1}\right)\end{array}$ & $\begin{array}{l}\text { Ethanol } \\
\left(\mathrm{g} \mathrm{L}^{-1}\right)\end{array}$ & $\begin{array}{l}\mathrm{Y}_{\text {se }} \\
\left(\mathrm{g}_{\text {ethanol }} / \mathrm{g}_{\text {total sugar }}\right)\end{array}$ \\
\hline 0 & 75.2 & 6.7 & 47.8 & 20.7 & 0.0 & - \\
20 & 16.7 & 5.1 & 0.4 & 11.1 & 30.0 & 0.47 \\
55 & 5.8 & 3.0 & 0.5 & 2.3 & 38.1 & 0.51 \\
\hline
\end{tabular}

The biomass was inoculated to a starting dry weight of $1.5 \mathrm{gL}^{-1}$. The sugar fraction indicated by DP2 includes amongst others cellobiose, melibiose, maltose and sucrose 
also contained $3 \mathrm{~g} \mathrm{~L}^{-1}$ acetic acid and $0.3 \mathrm{~g} \mathrm{~L}^{-1}$ of lactic acid, was supplemented with $0.4 \mathrm{~g} \mathrm{~L}^{-1}$ of $\left(\mathrm{NH}_{4}\right)_{2} \mathrm{PO}_{4}$ as a combined source of nitrogen and phosphate. Fermentations were run at $32{ }^{\circ} \mathrm{C}$, with an initial $\mathrm{pH}$ of 4.8 .

When batch cultures on the wheat straw hydrolysates were inoculated with $1.5 \mathrm{~g} \mathrm{~L}^{-1}$ of $S$. cerevisiae RWB 218 , most of the available sugars were converted within $55 \mathrm{~h}$ (Table 2). The yield of ethanol on the consumed sugars was very high and, towards the end of the fermentation, even approached the theoretical maximum yield of $0.51 \mathrm{~g} \mathrm{~g}^{-1}$. This very high apparent yield might partially be caused by the additional hydrolysis of some oligosaccharides or by the presence of other sugars that were not identified in the analyses. Xylitol formation was not observed.

Even when a much lower initial biomass concentration of $0.1 \mathrm{~g} \mathrm{~L}^{-1}$ was used, S. cerevisiae RWB 218 reached the same degree of conversion in $80 \mathrm{~h}$. Addition of vitamins, trace elements and/or the anaerobic growth factors Tween-80 and ergosterol $[2,3]$ did not result in a faster fermentation. This demonstrates the modest nutritional requirements of S. cerevisiae during fermentation of hydrolysates of lignocellulosic materials, which often contain very low levels of nutrients required for microbial growth.

\section{3}

\section{Fed-Batch Fermentation of Corn Stover Hydrolysate}

Corn stover is another potentially interesting feedstock for ethanol production, especially in the USA. The fermentation characteristics of S. cerevisiae RWB 218 on corn stover hydrolysate were tested under industrially relevant fed-batch conditions (W. de Laat, unpublished data). The corn stover pulp obtained after steam explosion $\left(190^{\circ} \mathrm{C}, 5 \mathrm{~min}, \mathrm{ENEA}\right.$, Italy) was diluted with water to $150 \mathrm{~g} \mathrm{~L}^{-1}$ dry matter and subsequently hydrolysed with $10 \mathrm{~g}$ cellulase protein (kg hydrolysate dry matter) $)^{-1}\left(\mathrm{GC} 220\right.$, Genencor, $96 \mathrm{~h}$ at $50^{\circ} \mathrm{C}$ ). After filtration, the resulting sugar solution contained $40 \mathrm{~g} \mathrm{~L}^{-1}$ glucose, $9 \mathrm{~g} \mathrm{~L}^{-1}$ D-xylose and $4 \mathrm{~g} \mathrm{~L}^{-1}$ acetic acid.

Fermentation experiments were initiated by a $32 \mathrm{~h}$ batch phase on molasses medium (containing $100 \mathrm{~g} \mathrm{~L}^{-1}$ sucrose, $\mathrm{pH} 4.8,32^{\circ} \mathrm{C}$ ) in a volume of $200 \mathrm{~mL}$. Subsequently, $455 \mathrm{~mL}$ of corn stover hydrolysate was added during a $16 \mathrm{~h}$ fed-batch phase. During the fed-batch phase, glucose was almost completely consumed. However, only $40 \%$ of the D-xylose fed to the culture was consumed during this phase (Fig. 9). After $16 \mathrm{~h}$, the fed-batch phase was terminated and the culture was allowed to consume accumulated sugars. Conversion was complete after $35 \mathrm{~h}$. At a biomass concentration of $1.0-1.5 \mathrm{~g} \mathrm{~L}^{-1}$, this corresponded to a D-xylose fermentation rate of $0.5 \mathrm{mmol} \mathrm{g}^{-1} \mathrm{~h}^{-1}$ during this latter phase. The overall ethanol yield on total sugars was $0.46 \mathrm{~g} \mathrm{~g}^{-1}$, which corresponds to $90 \%$ of the theoretical maximum yield on glucose and D-xylose. Consistent with the wheat straw hydrolysate fermentations, xylitol formation was not observed. 


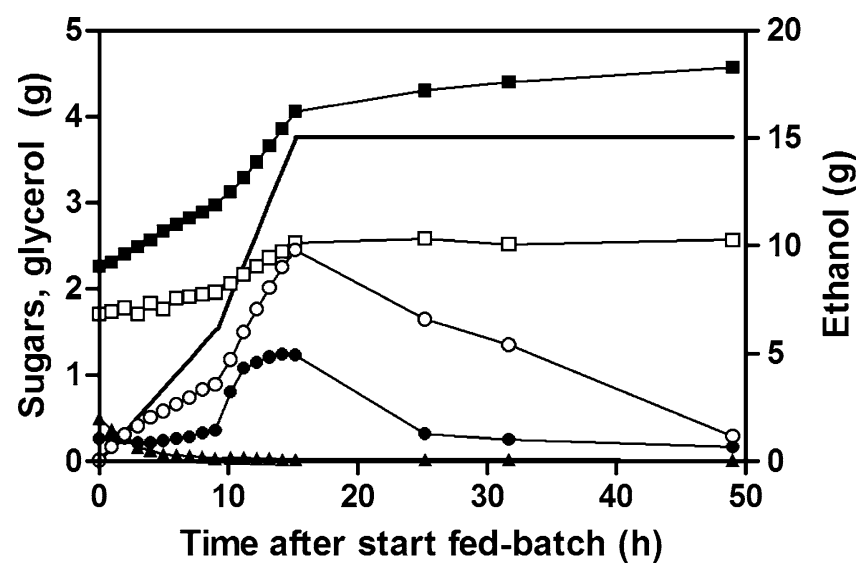

Fig. 9 Profiles of sugars and metabolites in an anaerobic corn stover hydrolysate fedbatch fermentation by S. cerevisiae RWB 218. Symbols indicate amounts of the following compounds present in the fermenter: glucose $(\bullet)$, D-xylose $(O)$, ethanol $(\boldsymbol{\square})$, glycerol $(\square)$, fructose $(\boldsymbol{\Delta})$ and cumulative added D-xylose (-). The experiments were initiated by a $32 \mathrm{~h}$ batch phase on molasses medium (containing $100 \mathrm{gL}^{-1}$ sucrose, $\mathrm{pH} 4.8,32^{\circ} \mathrm{C}$ ) in a volume of $200 \mathrm{~mL}$. Subsequently, $455 \mathrm{~mL}$ of corn stover hydrolysate (containing $40 \mathrm{~g} \mathrm{~L}^{-1}$ glucose, $9 \mathrm{~g} \mathrm{~L}^{-1} \mathrm{D}$-xylose and $4 \mathrm{gL}^{-1}$ acetic acid) was added during a $16 \mathrm{~h}$ fed-batch phase

\section{8}

\section{Outlook}

Functional expression in S. cerevisiae of a highly active fungal XI has paved the way for metabolic engineering of this yeast towards high-yield, rapid production of ethanol from D-xylose under fully anaerobic conditions. On theoretical grounds, this XI-based approach is superior to the extensively studied xylose reductase/xylitol dehydrogenase strategy. While considerable experimental proof to substantiate this statement has been obtained under "academic" conditions, a next important challenge is to do the same under industrial conditions. While the first experiments in real-life plant biomass hydrolysates are quite promising, there remains plenty of scope for integrating the D-xylose-fermentation genotype with other metabolic and processengineering strategies for further increased robustness under process conditions.

In addition to D-xylose, plant biomass hydrolysates contain several other potentially fermentable substrates that cannot be converted by wild-type S. cerevisiae strains [69]. While these compounds often represent only a few percent of the potentially fermentable carbon, they can have a decisive impact on economical competitiveness and sustainability of high-yield, high-volume processes such as fuel ethanol production. Functional integration of a highly efficient D-xylose fermentation pathway with pathways that are under devel- 
opment (e.g. arabinose $[9,36]$ ) or under consideration (e.g. rhamnose [69]) therefore presents an additional challenge in metabolic engineering for efficient fermentation of plant biomass hydrolysates. We are convinced that creative integration of metabolic engineering, evolutionary engineering and process design can result in rapid breakthroughs in these areas.

\section{References}

1. Amore R, Wilhelm M, Hollenberg CP (1989) Appl Microbiol Biotechnol 30:351

2. Andreasen AA, Stier TJB (1953) J Cell Comp Physiol 41:23

3. Andreasen AA, Stier TJB (1954) J Cell Comp Physiol 43:271

4. Asboth B, Naray-Szabo G (2000) Curr Protein Pept Sci 1:237

5. Attfield PV, Bell PJL (2006) FEMS Yeast Res 6:862

6. Bailey JE (1991) Science 252:1668

7. Barnett JA, Payne RW, Yarrow D (1990) Yeasts; characteristics and identification, 2 edn. Cambridge University Press, Cambridge, UK

8. Batt CA, Carvallo S, Easson DD, Akedo M, Sinskey AJ (1986) Biotechnol Bioeng 27:549

9. Becker J, Boles E (2003) Appl Environ Microbiol 69:4144

10. Benson DA, Karsch-Mizrachi I, Lipman DJ, Ostell J, Wheeler DL (2006) Nucleic Acids Res 34:16

11. Bhosale SH, Rao MB, Deshpande VV (1996) Microbiol Rev 60:280

12. Blow DM, Collyer CA, Goldberg JD, Smart OS (1992) Faraday Discuss 93:67

13. Briggs KA, Lancashire WE, Hartley BS (1984) EMBO J 3:611

14. Bruinenberg PM, de Bot PHM, van Dijken JP, Scheffers WA (1983) Eur J Appl Microbiol Biotechnol 18:287

15. Bruinenberg PM, de Bot PHM, van Dijken JP, Scheffers WA (1984) Appl Microbiol Biotechnol 19:256

16. Bruinenberg PM, van Dijken JP, Scheffers WA (1983) J Gen Microbiol 129:965

17. Dien BS, Cotta MA, Jeffries TW (2003) Appl Microbiol Biotechnol 63:258

18. Eide DJ, Clark S, Nair TM, Gehl M, Gribskov M, Guerinot ML, Harper JF (2005) Genome Biol 6:R77

19. Galbe M, Zacchi G (2002) Appl Microbiol Biotechnol 59:618

20. Garcia-Vallve S, Romeu A, Palau J (2000) Mol Biol Evol 17:352

21. Gárdonyi M, Hahn-Hägerdal B (2003) Enzyme Microb Technol 32:252

22. Gárdonyi M, Jeppsson M, Lidén G, Gorwa-Grauslund MF, Hahn-Hägerdal B (2003) Biotechnol Bioeng 82:818

23. Goodenough PW (1995) Mol Biotechnol 4:151

24. Grohmann K, Bothast RJ (1994) Pectin-rich residues generated by processing of citrus fruits, apples, and sugar beets: enzymatic hydrolysis and biological conversion to valueadded products. In: Himmel ME, Baker JO, Overend RP (eds) Enzymatic conversion of biomass for fuels production, Chap 19. Oxford University Press, New York, p 372

25. Gunsalus IC, Horecker BL, Wood WA (1955) Bacteriol Rev 19:79

26. Hahn-Hägerdal B, Wahlbom CF, Gárdonyi M, van Zyl WH, Cordero Otero RR, Johnsson LJ (2001) Adv Biochem Eng Biotechnol 73:53

27. Hamacher T, Becker J, Gárdonyi M, Hahn-Hägerdal B, Boles E (2002) Microbiology $148: 2783$

28. Harhangi HR, Akhmanova AS, Emmens R, van der Drift C, de Laat WTAM, van Dijken JP, Jetten MSM, Pronk JT, op den Camp HJM (2003) Arch Microbiol 180:134 
29. Ho NWY, Chen Z, Brainard AP (1998) Appl Environ Microbiol 64:1852

30. Hsiao HY, Chiang LC, Chen LF, Tsao GT (1982) Enzym Microb Technol 4:25

31. Ingram LO, Aldrich HC, Borges AC, Causey TB, Martinez A, Morales F, Saleh A, Underwood SA, Yomano LP, York SW, Zaldivar J, Zhou S (1999) Biotechnol Prog 15:855

32. Jeffries TW, Jin YS (2004) Appl Microbiol Biotechnol 63:495

33. Jeppsson M, Johansson B, Hahn-Hägerdal B, Gorwa-Grauslund MF (2002) Appl Environ Microbiol 68:1604

34. Johansson B, Hahn-Hägerdal B (2002) FEMS Yeast Res 2:277

35. Karhumaa K, Hahn-Hägerdal B, Gorwa-Grauslund MF (2005) Yeast 22:359

36. Karhumaa K, Wiedemann B, Hahn-Hägerdal B, Boles E, Gorwa-Grauslund MF (2006) Microb Cell Fact 5:R18

37. Klinke HB, Thomsen AB, Ahring BK (2004) Appl Microbiol Biotechnol 66:10

38. Kötter P, Amore R, Hollenberg CP, Ciriacy M (1990) Curr Genet 18:493

39. Kötter P, Ciriacy M (1993) Appl Microbiol Biotechnol 38:776

40. Kovarova-Kovar K, Egli T (1998) Microbiol Mol Biol Rev 62:646

41. Kumar S, Tamura K, Nei M (2004) Brief Bioinform 5:150

42. Kuyper M, Harhangi HR, Stave AK, Winkler AA, Jetten MSM, de Laat WTAM, den Ridder JJJ, op den Camp HJM, van Dijken JP, Pronk JT (2003) FEMS Yeast Res 4:69

43. Kuyper M, Hartog MM, Toirkens MJ, Almering MJ, Winkler AA, van Dijken JP, Pronk JT (2005) FEMS Yeast Res 5:399

44. Kuyper M, Toirkens MJ, Diderich JA, Winkler AA, van Dijken JP, Pronk JT (2005) FEMS Yeast Res 5:925

45. Kuyper M, Winkler AA, van Dijken JP, Pronk JT (2004) FEMS Yeast Res 4:655

46. Lee J (1997) J Biotechnol 56:1

47. Lonn A, Gárdonyi M, van Zyl WH, Hahn-Hägerdal B, Otero RC (2002) Eur J Biochem 269:157

48. Moes CJ, Pretorius IS, van Zyl WH (1996) Biotechnol Lett 18:269

49. Mussatto SI, Roberto IC (2004) Bioresour Technol 93:1

50. Niederberger P, Prasad R, Miozarri G, Kacser H (1992) Biochem J 287:473

51. Nissen TL, Anderlund M, Nielsen J, Villadsen J, Kielland-Brandt MC (2001) Yeast 18:19

52. Novick A, Szilard L (1950) Science 112:715

53. Novick A, Szilard L (1950) Proc Natl Acad Sci USA 36:708

54. Palmqvist E, Hahn-Hägerdal B (2000) Bioresour Technol 74:25

55. Petschacher B, Leitgeb S, Kavanagh KL, Wilson DK, Nidetzky B (2005) Biochem J 385:75

56. Richard P, Toivari MH, Penttilä M (2000) FEMS Microbiol Lett 190:39

57. Rodriguez-Pena JM, Cid VJ, Arroyo J, Nombela C (1998) FEMS Microbiol Lett 162:155

58. Rutgers M, Teixeira de Mattos JM, Postma PW, van Dam K (1987) J Gen Microbiol 133:445

59. Sarthy AV, McConaughy BL, Lobo Z, Sundstrom JA, Furlong CE, Hall BD (1987) Appl Environ Microbiol 53:1996

60. Sauer U (2001) Adv Biochem Eng Biotechnol 73:129

61. Schomburg I, Chang A, Ebeling C, Heldt C, Huhn G, Schomburg D (2004) Nucleic Acids Res 32:431

62. Sedlak M, Ho NWY (2004) Yeast 21:671

63. Sonderegger M, Sauer U (2003) Appl Environ Microbiol 69:1990

64. Toivari MH, Salusjarvi L, Ruohonen L, Penttilä M (2004) Appl Environ Microbiol 70:3681

65. Toivola A, Yarrow D, Van den Bosch E, van Dijken JP, Scheffers WA (1984) Appl Environ Microbiol 47:1221 
66. Traff KL, Otero Cordero RR, van Zyl WH, Hahn-Hägerdal B (2001) Appl Environ Microbiol 67:5668

67. van Dijken JP, Scheffers WA (1986) FEMS Microbiol Rev 32:199

68. van Hoek P, van Dijken JP, Pronk JT (2000) Enzyme Microb Technol 26:724

69. van Maris AJA, Abbott DA, Bellissimi E, van den Brink J, Kuyper M, Luttik MA, Wisselink HW, Scheffers WA, van Dijken JP, Pronk JT (2006) Antonie van Leeuwenhoek 60:391

70. Walfridsson M, Bao X, Anderlund M, Lilius G, Bulow L, Hahn-Hägerdal B (1996) Appl Environ Microbiol 62:4648

71. Wang PY, Schneider H (1980) Can J Microbiol 26:1165

72. Weikert C, Sauer U, Bailey JE (1997) Microbiology 143:1567

73. Wiebe MG, Robson GD, Oliver SG, Trinci AP (1994) Microbiology 140:3023 